\title{
Indian Pediatrics - Change of Guard: A Milestone but Miles to Go...
}

What are the skills expected from an Editor-in-Chief of a prestigious medical journal, and that too the official scientific publication of an organization as vibrant as 'Indian Academy of Pediatrics'? Most of us will agree that it is not an easy task; the editor is expected to possess writing, editing, administrative and negotiating skills, scientific and analytical mind, intellectual honesty, media savviness, and a thick hide $[1,2]$. I am not sure whether I possess all of these adequately but I think that I have the determination, willingness to learn, and expectation of gaining something from every piece I edit, every article that is rejected, and every feedback from the authors, readers and editorial board members. My association with 'Indian Pediatrics' for over 16 years in different capacities is definitely going to help me to continue to contribute to its growth, financial viability and reputation as a leading global medical journal.

Owing to the efforts of past editors and the members of the editorial team, the journal already enjoys an enviable position in the scientific world. However, we must not be complacent. My vision for 'Indian Pediatrics' includes further enhancing its popularity and utility for the target audience without compromising on the scientific rigor and academic integrity. While changes in content will be obvious, those related to the editorial process may not be directly visible to the readership but will indirectly affect the quality. From this issue, we are including structured abstract for 'Research Brief' section; structured abstract for 'Case Reports' has already been started from November 2013. For 'Editorials', we will invite different perspectives (preferably belonging to different fields) on an article published in the same issue to have a broader assessment and interpretation. The first such attempt in present volume is on an article about the role of nutritional rehabilitation centers for severe malnutrition. We also plan to start a 'Journal Club' on the same lines (See p.66), with inputs from various experts (pediatric practitioner, teaching faculty, public health personnel etc.) on current research articles published in leading pediatric journals.

'Indian Pediatrics' already has one of the shortest submission-to-decision times. Now, we need to reduce the decision-to-publication time. For transparent, uniform and rapid handling of manuscripts, we plan to structure
'Standard Operating Procedures' at various levels. This may initially seem to trouble the authors with more 'technical check failures' because of strict checklists given to the editorial staff but will ensure adherence to the recommended writing style. Ultimately, this will reduce the time-to-acceptance and will save the authors from multiple revisions requested at the time of final editing. We also plan to utilize applications such as 'Dropbox' and 'WhatsApp' for real time sharing of files in order to rapidly and effectively coordinate between editorial team and staff. Social media will also be utilized for wider dissemination of science; though ensuring effective protection from negative forces active on these sites would be a challenge.

Changes will not be made just for the sake of making changes. We will continue with the workshops on 'Art and Science of Paper Writing' for potential authors and reviewers while broadening its scope to other medical disciplines. We also envisage starting 'Research Methodology' workshops as demanded by most of the participants of paper writing course. We will ensure that our editorial board members are regularly updated in emerging issues and technologies in medical publishing by organizing a teaching-learning activity in every bimonthly meeting. We will continue with most of our popular sections such as 'Clippings', 'News', 'Images' and 'Reviews' besides retaining the broad structures of research article sections. However, for a system to work effectively, it has to be open. We urge readers to provide feedback and constructive criticism on the content, quality and process. Specific feedbacks will be published on the website, preferably in the same issue. I assure you of all my support to 'Indian Pediatrics' always.

Funding: None; Competing interests: None stated.

\section{REFERENCES}

Dheeraj Shah

Editor-in-Chief, Indian Pediatrics dheerajshah.indianpediatr@gmail.com

1. Collier R. No favour, no friends: parsing the qualifications for a journal's editor-in-chief. CMAJ. 2011;183:415-6.

2. Committee on Publication Ethics. COPE Best Practice Guidelines for Journal Editors. Available from: URL: publicationethics.org/files/u2/Best_Practice.pdf. Accessed December 12, 2013. 